\title{
Drug-reinforced responding: rapid determination of dose-response functions
}

\author{
G. Winger ${ }^{\mathrm{a}}$, R.K. Palmer ${ }^{\mathrm{a}}$ and J.H. Woods ${ }^{\mathrm{a}, \mathrm{b}}$ \\ ${ }^{\circ}$ Departments of Pharmacology and ${ }^{b}$ Psychology, University of Michigam, Ann Arbor, MI 48109 (U.S.A.)
}

(Received March 21st, 1989)

\begin{abstract}
Rhesus monkeys were conditioned to press on levers and receive intravenous infusions of cocaine or ketamine. Experimental conditions provided several different doses of drug during each of two daily 130 min sessions; as a result, a doseresponse curve relating rate of responding to dose/injection for self-administered drug was obtained within each session. Relative rate-maintaining effects of nomifensine and cocaine in monkeys on baseline conditions of cocaine self-administration, and rate-maintaining effects of ketamine, phencyclidine and MK-801 in monkeys on baseline conditions of ketamine selfadministration, compared favorably with relative rate-maintaining effects of these substances obtained in more traditional paradigms.
\end{abstract}

Key words: cocaine, nomifensine, phencyclidine, ketamine, MK-801, self-administration, rhesus monkeys

\section{Introduction}

In 1980, Woods [1] described in this journal a procedure for rapidly evaluating reinforcing effects of i.v. delivered codeine in rhesus monkeys. Using apparatus described by Deneau et al. [2], Woods conditioned monkeys to press on levers when a stimulus light was illuminated, and receive i.v. injections of codeine. Thirty responses were required for each injection, which was followed by a 10-min time out period during which the stimulus light was turned off and responses had no consequences. Each session was $130 \mathrm{~min}$ in duration, and a maximum of 13 injections could be earned in a session; two sessions occurred daily, separated by approximately 4 hours. Once baseline rates of behavior were established with $0.32 \mathrm{mg} / \mathrm{kg}$ per inj. codeine, substitutions of saline or one of several doses of codeine were made once every four sessions, which was equivalent to once every other day. A dose-response curve, relating dose of codeine to rate of responding maintained by that dose, could be obtained within 2-4 weeks.

Using this procedure, more than 180 opioid and non-opioid drugs have been evaluated [e.g., $3,4]$. In this paper, we evaluate a modification of this procedure, a modification that allows a dose-effect curve to be obtained for rate-maintaining effects of a drug in as few as one session. We evaluated cocaine and ketamine for their ability to maintain stable baseline rates of responding in two groups of monkeys, and observed effects of substituting the dopamineuptake blocker nomifensine in cocaine-baseline monkeys and the non-competitive NMDA antagonists phencyclidine and MK-801 in ketamine-baseline monkeys. We compared data obtained using the modified procedure with previously published data obtained with these drugs in the original procedure.

\section{Methods}

Subjects

Subjects were seven rhesus monkeys ( $\mathrm{Ma}$ caca mulatta) of either sex, weighing between 5.1 and $9.1 \mathrm{~kg}$. Monkeys were fed 125-185 grams of High Protein Purina Monkey Chow twice daily, at least $30 \mathrm{~min}$ prior to initiation of a self-administration session. Intravenous silastic catheters were surgically implanted in 
each monkey using $10 \mathrm{mg} / \mathrm{kg}$ i.m. ketamine and $15 \mathrm{mg} / \mathrm{kg}$ i.v. pentobarbital as anesthetic. Catheters were implanted in jugular, femoral, or brachial veins, as necessary. The catheter passed subcutaneously from the site of the incision to the mid-seapular region, where it exited the monkey and continued, through a hollow restraining arm, to the outside rear of the cage.

All but one subject had either short or long histories of self-administration of either cocaine or codeine under the conditions of the original paradigm. One monkey, in addition, had experience responding on the lever to terminate infusions of histamine or kappa opioids. One monkey's history was exclusively that of responding to terminate drug infusions.

\section{Apparatus}

The restraint and catheter protection device has been described in detail by Deneau et al. [2]. Monkeys were individually housed in stainless steel cages, measuring $83.3 \times 76.2 \times 91.4 \mathrm{~cm}$ deep. Each monkey wore a tubular stainless steel harness that protected the exit site of the catheter. A Teflon cloth jacket (Alice King Chatam Medical Arts, Los Angeles, CA) provided further protection for animals who tended to locate and pull their catheters. The harness was connected to a tubular, jointed arm that carried the catheter to the back of the cage where it joined tubing passing through a roller infusion pump (Watson and Marlow Co., Model MHRK 55; Falmouth, U.K.).

A $15.4 \mathrm{~cm}^{2}$ stimulus panel was located on the side of each cage, approximately $10 \mathrm{~cm}$ from the front and $19 \mathrm{~cm}$ from the bottom of the cage. Across the top of the stimulus panel, $2.5 \mathrm{~cm}$ apart, were three circles, $2.5 \mathrm{~cm}$ in diameter, covered with translucent plastic and capable of being illuminated from behind by 5 W Christmas tree bulbs. The two side lights could be illuminated red and the center light could be illuminated green. Below each of the two red stimulus lights was a response lever (Model 121-07; BRS-LVE, Beltsville, MD), capable of being operated by $10-15 \mathrm{~g}$ of force. Experimental control was provided by individual IBM PCjr computers located in an adjoining room. BASIC software was used to control experimental procedures.

\section{Procedure}

Monkeys were adapted to restraining arms for 1 week or more; then an i.v. catheter was implanted and they were given the opportunity to respond and receive drug. As with the original paradigm, experimental sessions were limited to $130 \mathrm{~min}$, and two sessions were scheduled each day, separated by at least 4 hours. Each session was divided into four components; each component was signaled by illumination of a red stimulus light, and was separated from the following component by a 10-min intercomponent interval. No lights were illuminated, and responses had no consequences during the intercomponent interval.

Except as noted below, a unique dose per injection of drug was available during each component. A component ended after 20 injections of that particular dose were earned, or 25 min had passed, whichever occurred first. Drugs were delivered on a fixed ratio 30 schedule and each injection was followed by a $45 \mathrm{~s}$ time out period, during which the red light was extinguished and responses had no consequences. Injections were accompanied by illumination of the center, green stimulus light. Drug concentration was kept constant throughout a session; doses/inj. were altered by adjusting duration of the infusion pump, which delivered $1 \mathrm{~cm}^{3}$ of drug solution per $5 \mathrm{~s}$. The shortest duration was $0.1 \mathrm{~s}$ and always corresponded to a dose of ' 0 ' on the dose-effect curves. Other doses, evaluated in one-half logarithm unit steps, were associated with 1.7, 5.0 and $16.7 \mathrm{~s}$ infusion durations. A concentration of $0.05 \mathrm{mg} / \mathrm{cm}^{3}$ for a $5 \mathrm{~kg}$ monkey would result in doses of $0.003 \mathrm{mg} / \mathrm{kg}$ per inj. at an infusion duration of $1.7 \mathrm{~s}\left(0.3 \mathrm{~cm}^{3}\right), 0.01 \mathrm{mg} / \mathrm{kg}$ per inj. at an infusion duration of $5 \mathrm{~s}\left(1 \mathrm{~cm}^{3}\right)$, and $0.03 \mathrm{mg}$ / $\mathrm{kg}$ per inj. at an infusion duration of $16.7 \mathrm{~s}(3.3$ $\mathrm{cm}^{3}$ ). Four different permutations of these infusion durations were used. Each infusion duration appeared in a different position in the selected permutations: $0.1,1.7,5.0$ and $16.7 \mathrm{~s}$; 
1.7, 0.1, 16.7 and $5.0 \mathrm{~s} ; 5.0,16.7,1.7$ and $0.1 \mathrm{~s}$ and $16.7,5.0,0.1$ and $1.7 \mathrm{~s}$. These four permutations were used exclusively, with nearly equal frequency, except during the time behavior was being established.

When a monkey was first exposed to the new procedure, dose/inj. was usually left constant ( $0.003 \mathrm{mg} / \mathrm{kg}$ per inj. cocaine or 0.03 or $0.1 \mathrm{mg} /$ kg per inj. ketamine) using 5 -s infusion durations in each of the four components until rates of responding were greater than one response per second. The range of drug doses was then introduced, and behavior was allowed to stabilize. The range of doses was empirically selected so as to produce a monotonically increasing dose-response function. Thus, we selected for evaluation the ascending limb of the characteristically inverted U-shaped function relating dose/inj. to rate of drug selfadministration [e.g., 5].

After response rates became relatively stable, saline was substituted for the baseline drug. The number of sessions before saline was substituted varied from eight to 60 (mean $=$ 36), but since there was no strict criteria as to when behavior was considered stable, this number does not reflect precisely the time required for behavior to become sufficiently stable to proceed with evaluation of other drugs.

When saline was substituted, infusion durations continued to be varied, as they were under drug condition, and the order of infusion durations was the order that would have been used for that session if the drug had been available. If rates of saline-maintained responding were higher than approximately 0.5 responses per second at any infusion duration, saline was substituted again, two or three sessions later, until rates were consistently below 0.5 responses per second. If rates of salinemaintained responding were quite high, consecutive saline sessions were given until rates declined. Saline substitutions continued on a periodic basis, three to four times each week, throughout the experiment.

Test drugs were substituted during single sessions after rates of saline-contingent behav- ior were consistently lower than rates of cocaine- or ketamine-contingent behavior. Although rates of responding maintained by three doses (plus the " 0 " dose indicated by 0.1 -s infusion durations) of test drug were measured in each session in which these drugs were evaluated, it was frequently the case that effects of additional doses needed to be examined. This was accomplished by retesting that drug using a different concentration of drug solution, thereby evaluating a different range of three doses. All data obtained from a given drug were averaged together; some data points therefore include data obtained when that dose was available at more than one infusion duration.

\section{Drugs}

Cocaine was purchased from Mallinckrodt, Inc., St. Louis, MO; phencyclidine and ketamine, from Warner Lambert/Parke-Davis, Morris Plains, NJ. Nomifensine was supplied by Hoecht-Roussel Pharmaceutical, Sommerville, NJ and MK-801, by Merck Sharp and Dohme Research Laboratory, Rahway, NJ. All drugs were prepared in sterile water.

\section{Results}

\section{Cocaine-baseline}

Once baseline rates of responding appeared sufficiently stable, data from sixteen nearly consecutive sessions (exceptions were sessions in which saline or another drug was substituted) of cocaine availability were evaluated for effects of cocaine dose and dose order. The four doses of cocaine maintained differential self-administration behavior within single 130-min experimental sessions. Rate of responding maintained by cocaine increased as dose of cocaine increased, as shown in Fig. 1. The highest rate of responding for each monkey occurred at the largest dose tested, $0.01 \mathrm{mg} / \mathrm{kg}$ per inj.

The order of dose presentation did not greatly affect the dose-response relation. Figure 2 shows that low rates of responding occurred at $0 \mathrm{mg} / \mathrm{kg}$ per inj., high rates 


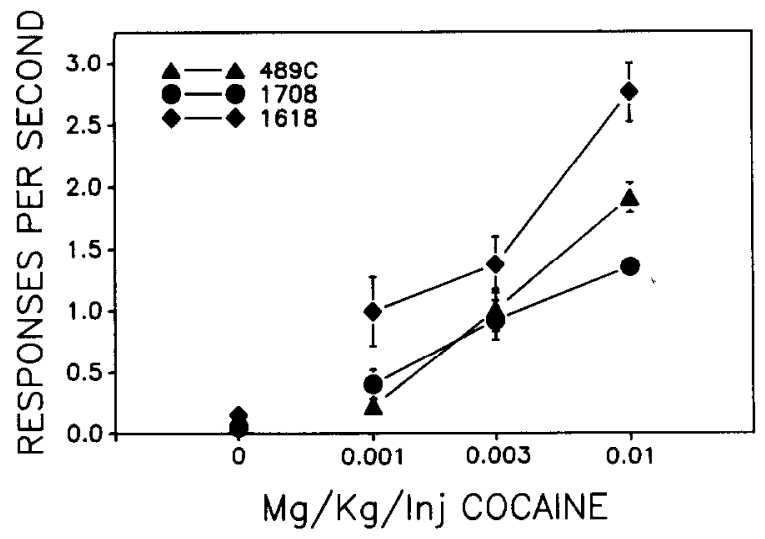

Fig. 1. The ability of various doses of cocaine to maintain responding in three monkeys under conditions in which several doses of the drug were available in individual 130min sessions. The symbols represent rates of responding averaged across 16 sessions for each monkey. Vertical lines are standard errors of the mean. occurred at $0.01 \mathrm{mg} / \mathrm{kg}$ per inj. and intermediate rates occurred at 0.001 and 0.003 $\mathrm{mg} / \mathrm{kg}$ per inj., irrespective of the dose order within a session. Greater variability across dose-presentation order was noticeable at 0.001 and $0.003 \mathrm{mg} / \mathrm{kg}$ per inj.; however, few consistent trends in rates as a function of dose order appeared across monkeys. The only possible exception to this was when the dose order was $0.001,0,0.01$ and $0.003 \mathrm{mg} / \mathrm{kg}$ per inj. In this order, the dose of $0.003 \mathrm{mg} / \mathrm{kg}$ per inj was consistently self-administered at lower rates than when it was available earlier in the order. Although, in the case of monkey 1618, rates of responding maintained by $0.001 \mathrm{mg} / \mathrm{kg}$ per inj were considerably higher when this dose was third in the dose order, as compared to when it was first, second, or fourth, this

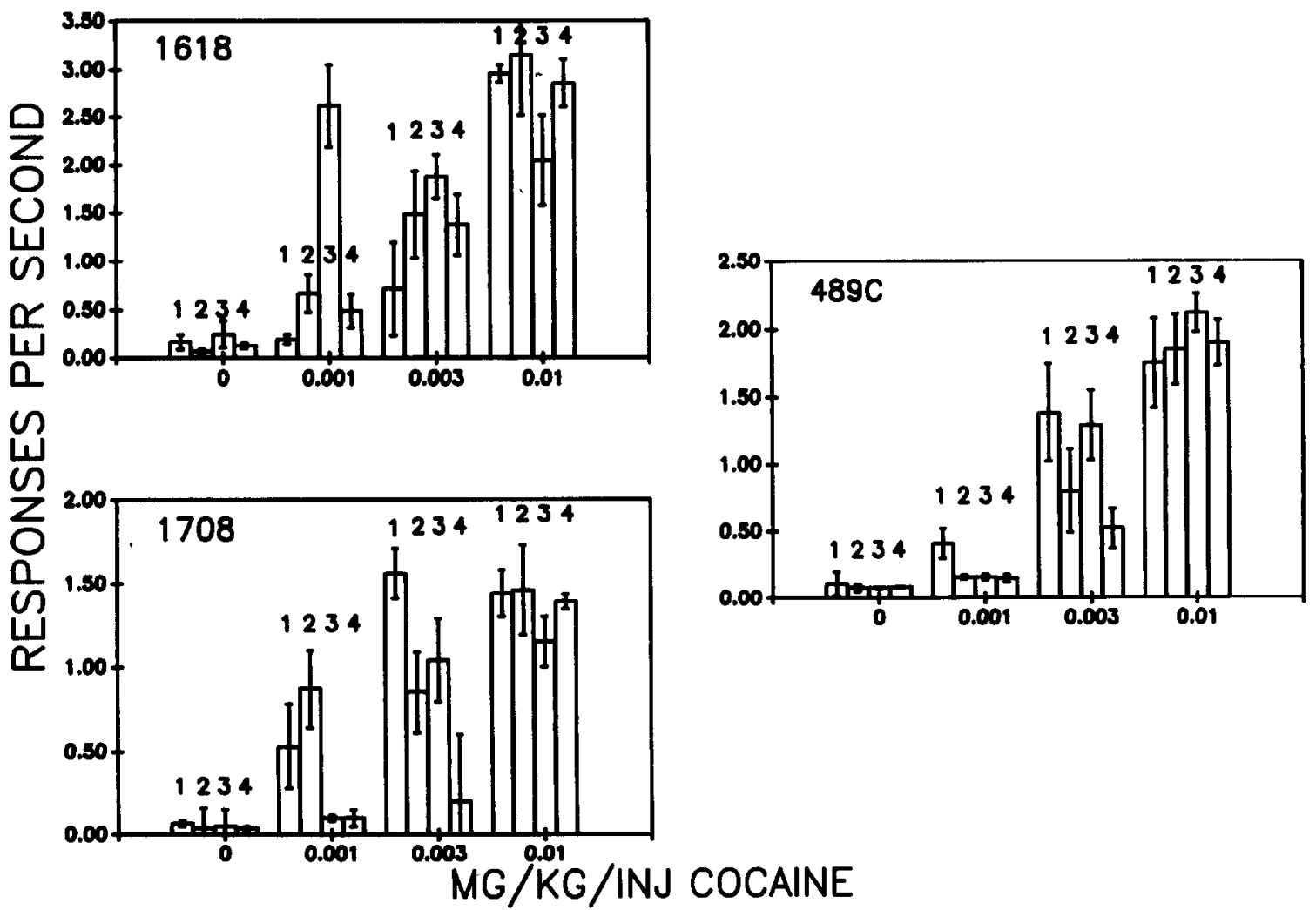

Fig. 2. The effect of order of dose presentation on rate of responding maintained by cocaine in each of three monkeys. The numbers at the top of each column indicate the order (first, second, third or fourth) of that particular dose in a daily sequence of dose presentation. Four unique sequences were used, selected so that each dose was in a different position across the four sequences. The columns are averages of four observations of rates of responding maintained by the indicated doses in the indicated sequence orders. Vertical lines are standard errors of the mean. 
order effect was not observed in the other two monkeys. Closer examination of data from monkey 1618 indicated that this effect was most likely a sampling error; similar order effects were not observed in another sample of sessions.

When several doses/infusion of nomifensine were substituted for cocaine within single sessions, nomifensine was found to maintain responding as well (Fig. 3). In two of the three monkeys evaluated with nomifensine, the drug appeared nearly identical to cocaine in both potency and efficacy. It was slightly more potent than cocaine in the third monkey (489C).

\section{Ketamine-baseline}

The ability of ketamine, phencyclidine and MK-801 to maintain responding using this procedure was compared in three monkeys maintained on a baseline of ketamine selfadministration. As shown in Fig. 4, phencyclidine was as effective as ketamine as a reinforcer; both drugs produced increases in response rates as dose/injection was increased, and showed similar maximum rates of responding. Phencyclidine was approximately ten times more potent than ketamine as a reinforcer. MK-801 also appeared to be more potent than ketamine, but it did not maintain

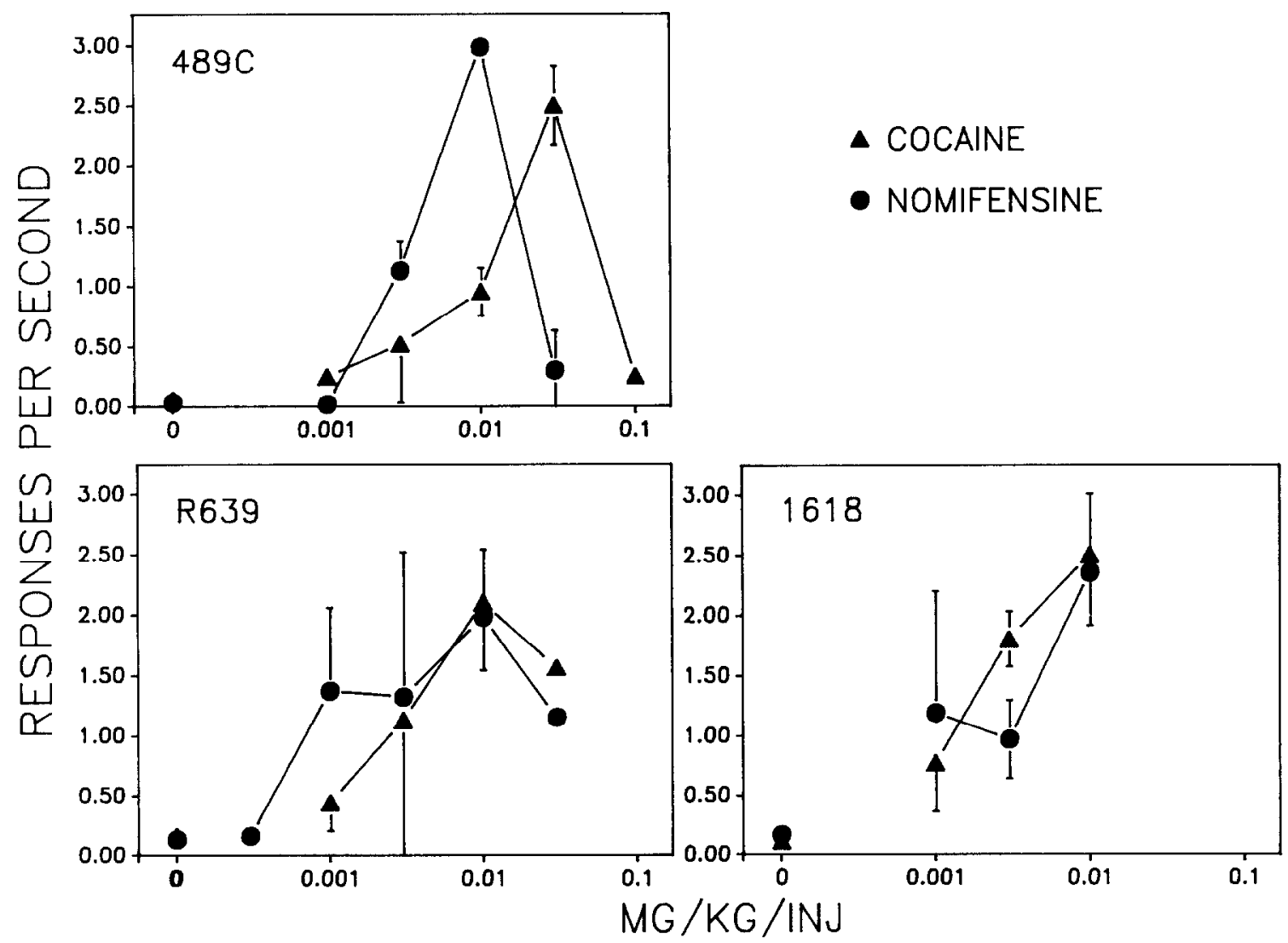

Fig. 3. Rates of responding maintained by cocaine and by nomifensine in each of three monkeys. Nomifensine was presented twice to monkey $489 \mathrm{C}$, once using a dose range of $0.001-0.01 \mathrm{mg} / \mathrm{kg}$ per inj. and once using a dose range of $0.003-0.03 \mathrm{mg} / \mathrm{kg}$ per inj. Nomifensine was presented four times to monkey $\mathbf{R 6 3 9}$, once at a dose range of $0.0001-0.001 \mathrm{mg} / \mathrm{kg}$ per inj. once at a dose range of $0.0003-0.003 \mathrm{mg} / \mathrm{kg}$ per inj. and twice at a dose range of $0.001-0.01 \mathrm{mg} / \mathrm{kg}$ per inj. Nomifensine was presented four times to monkey 1618 , each time at the dose range of $0.001-0.01 \mathrm{mg} / \mathrm{kg}$ per inj. Comparative data on rates of responding maintained by cocaine were obtained from the session just prior to that in which nomifensine was substituted, with the addition, in the case monkeys $\mathrm{R639}$ and $489 \mathrm{C}$, of two and three sessions, respectively, in which a higher dose range of cocaine $(0.003$ -0.03 and $0.01-0.1 \mathrm{mg} / \mathrm{kg}$ per inj., respectively) was substituted. Vertical lines are standard errors of the mean. 


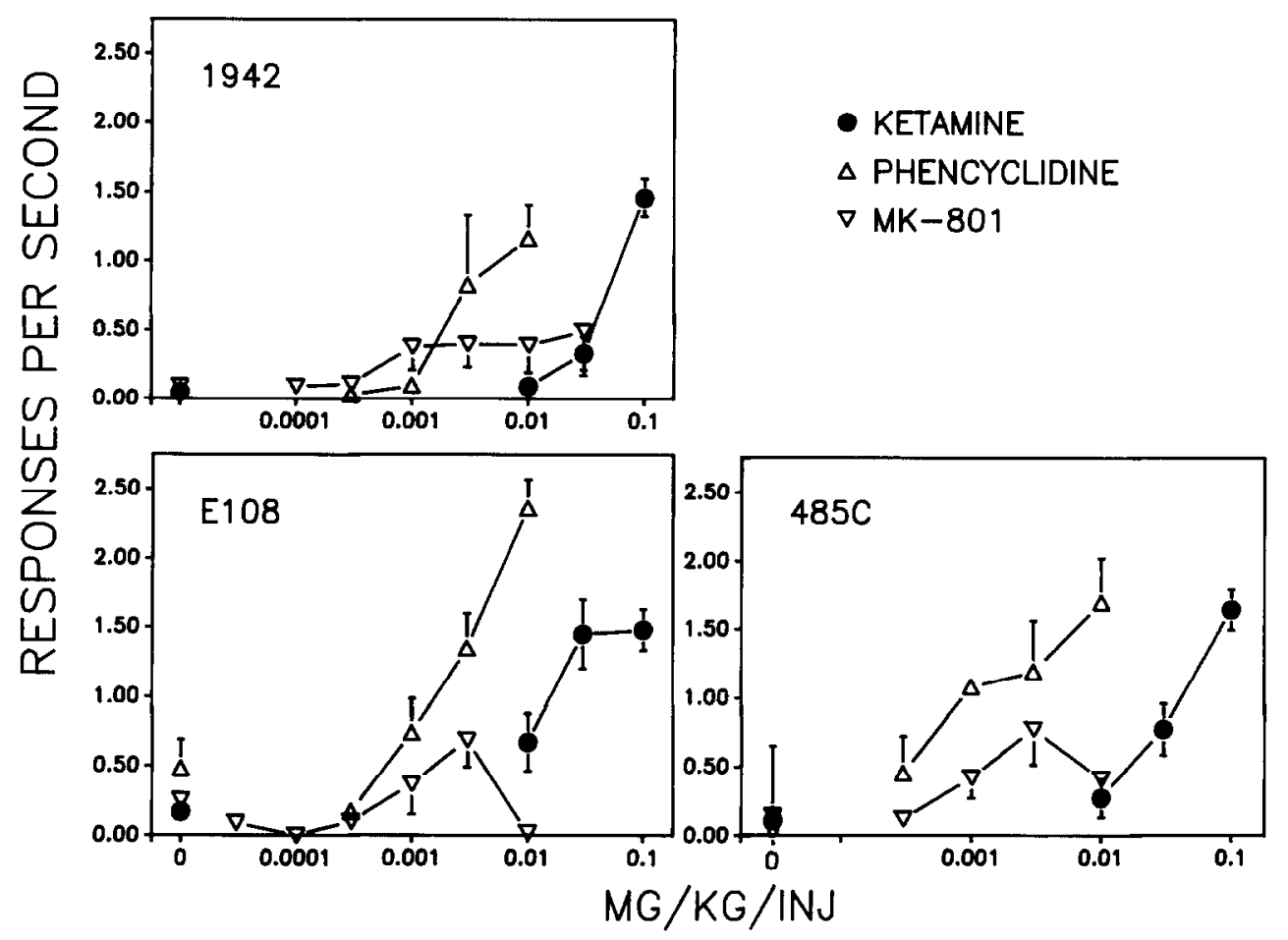

Fig. 4. Rates of responding maintained by ketamine, phencyclidine and MK- 801 in each of three monkeys who were experienced with ketamine self-administration. Phencyclidine was presented to monkey E108 once at a dose range of $0.0003-0.003$ $\mathrm{mg} / \mathrm{kg}$ per inj. and twice at a dose range of $0.001-0.01 \mathrm{mg} / \mathrm{kg}$ per inj.; to monkey $485 \mathrm{C}$ twice at a dose range of $0.0003-0.003$ $\mathrm{mg} / \mathrm{kg}$ per inj. and three times at a dose range of $0.001-0.01 \mathrm{mg} / \mathrm{kg}$ per inj,; to monkey 1942 once at a dose range of $0.0003-$ $0.003 \mathrm{mg} / \mathrm{kg}$ per inj. and four times at a dose range of $0.001-0.01 \mathrm{mg} / \mathrm{kg}$ per inj. Each of the three monkeys was tested with MK-801 on several occasions (12 times for monkey 1942, nine times for monkey E108, and six times for monkey $485 \mathrm{C}$ ) at dose range from 0.00003 to $0.03 \mathrm{mg} / \mathrm{kg}$ per inj. Comparative data on rates of responding maintained by ketamine were obtained from the sessions just prior to those in which phencyclidine or MK-801 was substituted.

rates of responding that were as high as those maintained by phencyclidine or ketamine (Fig. 4). A fairly wide range of doses of $\mathrm{MK}-801$ was evaluated in these monkeys; in one subject (1942) MK-801 produced a fairly flat dose-effect. curve rather than the sharply increasing doseeffect curve that developed with the other tested drugs. The dose-effect curve was steeper in the other two monkeys, but did not reach the same maximum as did ketamine or phencyclidine.

\section{Discussion}

In the current procedure, as in the previous procedure, each drug tested maintained selfadministration behavior, and the dose of drug tested was the strongest determinant of rates of responding. Each drug except MK-801 was more potent in maintaining behavior in the current procedure than it was in the previous procedure. This is to be expected since, with shorter time out periods between infusions (45 $s$ vs. $10 \mathrm{~min}$ ), lower doses of drug should maintain rates of responding. In studies by Downs and Woods [4], in which various doses of cocaine were available on an FR 30 schedule with no time out period, the maximum rate of responding occurred at a dose of $0.003 \mathrm{mg} / \mathrm{kg}$ per inj. In contrast, with the same fixed ratio parameters but with a 10 -min time out period between injections, the maximum rate of responding occurs at a dose of $0.32 \mathrm{mg} / \mathrm{kg}$ per inj. cocaine [5]. 
The data suggest that the influence of time out duration on the rate of drug-maintained responding is relatively greater if the drug is short acting. Cocaine, a very short-acting compound, maintained maximum rates of responding at $0.32 \mathrm{mg} / \mathrm{kg}$ per inj. in the original procedure [5] and at $0.01 \mathrm{mg} / \mathrm{kg}$ per inj. in the current procedure, a difference of 1.5 logarithm units. Nomifensine and ketamine, both shortacting drugs, showed a difference of 1 logarithm unit between the two procedures $(0.1$ $\mathrm{mg} / \mathrm{kg}$ per inj. [5] vs. $0.01 \mathrm{mg} / \mathrm{kg}$ per inj. for nomifensine, $1.0 \mathrm{mg} / \mathrm{kg}$ per inj. (unpublished observations) vs. $0.1 \mathrm{mg} / \mathrm{kg}$ per inj. for ketamine). Phencyclidine, with a longer duration of action, showed a difference of $1 / 2$ logarithm unit $(0.03 \mathrm{mg} / \mathrm{kg}$ per inj. [6] vs. 0.01 $\mathrm{mg} / \mathrm{kg}$ per inj.) in the two procedures. There was little difference in the potency of MK- 801 in the two procedures; the maximum rate-maintaining effect in both was $0.003 \mathrm{mg} / \mathrm{kg}$ per inj. [6]. In our experience, MK-801 has a slower onset of action and a longer duration of action than does phencyclidine. It might be expected that, if drug accumulation is important in determining rates of drug-reinforced responding, responding maintained by drugs with longer durations of action, drugs that accumulate nearly equally with either a $45 \mathrm{~s}$ or a 10-min time out, would be less influenced by time out duration than shorter acting drugs.

Although there were inconsistent differences among potencies of various drugs in the current procedure as compared with the previous procedure, there was little difference in the relative magnitude of the drugs' effects. Cocaine and nomifensine maintained nearly equal maximum rates of responding in the prior procedure, and nearly equal maximum rates of responding in the current procedure. Absolute rates of responding maintained by cocaine and nomifensine were somewhat higher in the prior procedure, but individual differences in rates of responding are often large in both procedures, and the significance of these differences is probably slight.

In the prior procedure, rates of responding maintained by the baseline dose of ketamine $(0.56 \mathrm{mg} / \mathrm{kg}$ per inj.) were slightly higher than the maximum rates maintained by phencyclidine in two of the three monkeys and were nearly identical for the third monkey [6]. In the current procedure, ketamine and phencyclidine maintained equal rates in one monkey, phencyclidine maintained higher rates in one monkey and ketamine maintained slightly higher rates in one monkey. Thus, there was little overall difference in the two procedures. Patterns of self-administration of MK-801 were similar in the two procedures in that the slope of the curve relating dose of drug to rate of responding was relatively shallow. Also, MK801 did not maintain as high a rate of responding in either procedures as did phencyclidine or ketamine.

It thus appears that a procedure in which several doses of a drug are available for selfadministration in a single session can provide data very comparable to data obtained in a paradigm in which only a single dose of drug is evaluated in a single session. The most important advantage of this procedure is that it allows dose-effect curves, relating dose of drug to rate of responding, to be obtained quickly. In comparison to the procedure described by Woods [1], in which 6 days were the minimum necessary to determine the effects of three doses of drug on rate of responding, a similar dose-effect curve can be obtained in $130 \mathrm{~min}$ using the procedure described here. Other procedures in which each dose of a drug is substituted for the baseline drug for several days [e.g., 7] may require even longer periods to obtain a dose-effect curve. Yet, although the potency relations among and within drugs may vary from procedure to procedure, the different procedures agree quite well when asking the general question of whether a particular drug is a reinforcer or not.

A rapid procedure for evaluation of drug self-administration behavior can be helpful in a number of situations. For example, studies of the effects of a large number of potential drug intervention strategies on drug self-administration are more feasible in this procedure. The rapidity of obtaining dose-rate curves also allows evaluations that would be difficult or impossible to obtain in some of the other 
procedures. The effects of tolerance and dependence on drug self-administration are difficult to measure using most protocols, because the amount of tolerance and dependence can vary during the intervals between evaluation of the reinforcing effects of various drug doses. In the current procedure, shifts in dose-effect curves as a function of chronic drug administration can be evaluated in a short period of time, before additional physiological changes occur. We hope that applications of this procedure will provide much additional information on characteristics of drugs of abuse.

\section{Acknowledgements}

Work was supported by Public Health Service Grants DA 05325 and DA 04403. Technical assistance of Laurie Heller is greatly appreciated.

\section{References}

1 J.H. Woods, Drug Alcohol Depend., 5 (1980) 223.

2 G.A. Deneau, T. Yanagita and M.H. Seevers, Psychopharmacologia 16 (1969) 30.

3 G. Winger and J.H. Woods, Drug Alcohol Depend., 15 (1985) 123.

4 A. Young et al., J. Pharmacol. Exp. Ther., 229 (1984), 118.

5 D.A. Downs and J.H. Woods, J. Pharmacol. Exp. Ther., 191 (1974) 179.

6 W. Koek, J.H. Woods and G.D. Winger, J. Pharmacol. Exp. Ther., 245 (1988) 969.

7 R.R. Griffiths, J.V. Brady and G.E. Bigelow, in: T. Thompson and C.E. Johanson (Eds.), Behavioral Pharmacology of Human Drug Dependence. NIDA Res. Mono. Series No. 37. U.S. Government Printing Office, 1981, p. 182. 